\title{
Reabilit: estudo de caso em uma instituição assistencial de saúde no recife e a influência da iluminação nas atividades terapêuticas.
}

\author{
Reabilit: case study in a health care institution at recife and the influence of \\ lighting in therapeutic activities.
}

\author{
LÔBO, Marcella \\ Universidade Federal de Pernambuco, Mestranda em Design \\ marcellavlobo@gmail.com
}

\author{
VILLAROUCO, Vilma \\ PPGDesign-UFPE; PPErgo-UFPE; PPGAU+D-UFC; Dra. em Engenharia \\ vvillarouco@gmail.com
}

\begin{abstract}
RESUMO
Instituições de reabilitação desenvolvem atividades de tratamento para pacientes com disfunções cognitivas e motoras. O presente artigo tem como objetivo apresentar um estudo sobre a importância da iluminação no tratamento diário dos usuários desse tipo de estabelecimento, dispondo a luz como fonte de reforço à assimilação intelectual do ser humano. O estudo de caso foi executado em uma clínica de terapias integradas, na cidade de Recife. A ausência de considerações acerca do tema resultou na importância da efetivação da pesquisa, a fim de obter dados capazes de incrementar o processo de revitalização do paciente, promovendo um produto proficiente à concepção de espaços similares. Pautada na Metodologia Ergonômica para o Ambiente Construído, de Villarouco (2009), a pesquisa foi subdivida em etapas de avaliação da área, ora fisicamente, ora perceptualmente, considerando a visão do usuário por meio de questionários e experimentos. O pressuposto inicial foi corroborado, quando obteve-se na pesquisa que a iluminação fornece estímulos visuais e psíquicos nos usuários, sendo fortemente positiva naqueles com disfunções cognitivas.

Iluminação, Tratamento Terapêutico, Percepção do Usuário, Ergonomia do Ambiente Construído, Desenvolvimento Cognitivo.
\end{abstract}

\begin{abstract}
Rehabilitation institutions develop treatment activities for patients with cognitive and motor disabilities. The present article aims to present the importance of lighting in the daily treatment to the users of this establishment type, providing the light as a source of improvement to the intellectual assimilation of the human being. The case study was carried out at an integrated therapy clinic titled Reabilit, at Recife. The absence of considerations about the subject resulted in the importance of the research effectiveness, in order to obtain data capable of increasing the patient revitalization process, and promoting a product proficient in the design of similar spaces. Based on the Ergonomic Methodology for the Built Environment, by Vilma Villarouco (2009), the research was subdivided into areas of space's evaluation, both physically
\end{abstract}




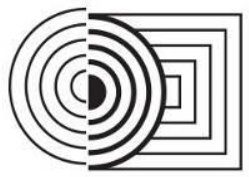

\section{$17^{\circ}$ ERGODESIGN \& USIHC 2019 \\ PUC-Rio, 11 a 13 de dezembro \\ Rio de Janeiro, RJ, Brasil}

$17^{\circ}$ Ergodesign - Congresso Internacional de Ergonomia e Usabilidade

de Interfaces Humano Tecnológica: Produto, Informações Ambientes

Construídos e Transporte

$17^{\circ}$ USIHC - Congresso Internacional de Ergonomia e Usabilidade

de Interfaces Humano Computador

and sometimes psychologically, considering the user's vision through questionnaires and experiments. As predicted, it was found that the lighting provides visual and psychic stimuli in the users, being surprisingly positive in those with cognitive dysfunctions.

Illumination, Therapeutic Treatment, User Perception, Ergonomic of the Constructed Environment, Cognitive Development.

\section{INTRODUÇÃO}

A Arquitetura foi criada a partir da necessidade do homem de abrigo e proteção. Ao longo do seu desenvolvimento, foram necessárias adaptações que se tornaram essenciais na atuação e concepção de projetos arquitetônicos. Somou-se a esses estudos a ergonomia aplicada aos ambientes construídos, colocando muito fortemente o foco no ser humano, usuário dos espaços. Uma das importantes vertentes nessa área, o conforto lumínico, disponibiliza vasta gama de possibilidades de abordagens e representa o objeto da pesquisa aqui exposta.

Segundo Villarouco (2002) o olhar do profissional deve prever aspectos importantes da utilização do ambiente e associar a eles os condicionantes relevantes - que podem ser físicos, cognitivos, antropométricos, da acessibilidade, psicossociais e culturais - a fim de minimizar as possibilidades de uma insuficiência ainda mesmo na fase conceitual do projeto.

Analisando o ambiente construído para o tratamento de reabilitação motora e mental, foi possível inferir que é de suma importância, para um aumento na capacidade de absorção cerebral das informações, uma correta iluminação do ambiente de atendimento, facilitando a dinâmica do terapeuta e a compreensão da atividade pelo paciente em questão.

O desenvolvimento das funções é o ponto de partida para a usabilidade do estabelecimento que servirá como estudo de caso para este artigo. O local selecionado, uma clínica de terapias integradas, possui sobretudo pacientes com lacunas motoras, cognitivas e comportamentais, entre tantas outras necessidades especiais.

$\mathrm{Da}$ abordagem do ambiente deste estabelecimento, configurou-se a necessidade de aprofundamento acerca da iluminação como ponto de auxílio no desenvolvimento das terapias executadas nesses pacientes, gerando a pergunta para a pesquisa: como a iluminação poderia interferir na resposta do paciente ao tratamento diário?

Como objeto de pesquisa, foram selecionadas duas salas em pleno funcionamento para a atividade de observação. Elas funcionam com dois tipos de terapia que influenciaram diretamente no teor da pesquisa. Em ambas, existe uma iluminação proposta previamente, por isso, este artigo avalia a luminotécnica a partir da comparação de valores medidos in loco e dados normativos.

$\mathrm{Na}$ primeira sala acontece um atendimento mais voltado para terapia ocupacional, uma atividade de saúde que presta serviços de melhoria para o desempenho funcional do paciente, a fim de prevenir atraso ou incapacidade no desenvolvimento de alguma ação. E na segunda se encontra uma sala exclusiva de fisioterapia, voltada para tratamentos traumatológicos e regenerativos, onde comumente são abordados elementos de recuperação.

$\mathrm{Na}$ pesquisa realizada na literatura especializada, não foram localizados modelos e estudos voltados para a elaboração de projetos em ambientes desta natureza, apenas em espaços hospitalares ou de longa permanência. Nesse sentido, consideram-se os benefícios que este estudo pode indicar para projetos futuros, gerando diretrizes para os projetistas, e melhorando a capacidade de atenção e de resposta dos usuários, uma das tantas características obtidas através da luz quando corretamente aplicada. 
Partindo do princípio de que uma combinação de meios proficientes auxilia na obtenção de resultados positivos, tem-se desenvolvido neste estudo, através de resultados obtidos em campo, um mapeamento de informações que podem levar a um melhor aproveitamento do local estudado, sintetizando, através resultados obtidos, a influência da iluminação no desenvolvimento dos usuários observados.

\section{FUNDAMENTAÇÃO TEÓRICA}

Este trabalho está situado na área da Ergonomia do Ambiente Construído (EAC) que consiste em um recente ramo da ergonomia que se preocupa com a adequação de ambientes às atividades que nele se desenvolvem e às necessidades de seus usuários. Esta pesquisa adotou o estudo de caso, realizando-o em duas salas de uma clínica multidisciplinar.

Encontram-se informações acerca da relação da luz (natural ou artificial) e as questões de saúde em diversos campos da Arquitetura, pois quase tudo que existe depende "[...] da luz solar. Ela governa as nossas vidas, estabelecendo ritmos fisiológicos e o ciclo de atividades como acordar, dormir, comer e trabalhar. Além disso ela tem um efeito benéfico sobre 0 organismo, melhorando a saúde e o humor". (IIDA, 2005, p.50)

$\mathrm{Na}$ área de projetos relacionados ao conforto ambiental hospitalar tem-se que a correta utilização da luz pode influenciar no tempo e na capacidade de cura dos pacientes, sendo extremamente positiva quando abordada de maneira a relaxar e remeter ao aconchego disponível nos ambientes residenciais (PECCIN, 2002, apud. BENYA, 1989), além de tornar possível um aprimoramento na execução de atividades que exigem concentração, bem como um aumento considerável na criatividade.

De acordo com esses dados, a presente pesquisa partiu do pressuposto que através da utilização de recursos luminotécnicos pacientes neurológicos e motores poderão ser estimulados para um melhor alcance do tratamento diário executado em clínicas de reabilitação.

Inserindo os estudos da luminotécnica nos domínios da ergonomia, tem-se como relevante o estudo realizado, visto que o resultado pode contribuir na definição dos conceitos e prioridades projetuais futuros. Com isso, a pesquisa pretende incrementar o nível de informação abordada no quesito arquitetônico e ergonômico para esses ambientes através da comprovação das informações e da sintetização dos resultados obtidos. Dessa forma, além do resultado poder ser percebido no âmbito da saúde e integridade do paciente, ele também proporcionará benefícios em relação ao espaço utilizado e ao profissional atuante.

\section{METODOLOGIA}

A pesquisa adotou a Metodologia Ergonômica para o Ambiente Construído - MEAC (VILLAROUCO, 2009), que consiste em uma avaliação ergonômica desenvolvida em etapas. A abordagem para este estudo foi dividida em três partes: duas análises obtidas em situações reais existentes em campo e uma terceira desenvolvida em situação simulada pelo pesquisador.

A primeira etapa consiste na parte física do projeto, subdividida em três etapas conforme prevê a MEAC. Inicialmente houve uma Análise Global do Ambiente, ou seja, uma visita de campo a fim de compreender o ambiente a ser analisado e suas atividades como executadas sem nenhuma intervenção. Em seguida, foi elaborada a Identificação da Configuração Ambiental, onde são apresentados todos os condicionantes físico-ambientais, através da obtenção de todos os dados do ambiente, sejam eles normativos ou projetuais, com isso 
puderam ser encontradas as primeiras influências do ambiente nas atividades nele executadas. $\mathrm{Na}$ última etapa, de ordem física, tem-se a Avaliação do Ambiente em Uso, produzida através da observação do uso do espaço em questão, a fim de perceber seus pontos positivos e negativos para as funções nele trabalhadas.

A segunda fase é de ordem perceptiva, quando são inseridos conceitos e ferramentas da psicologia ambiental. Nela são implementados instrumentos capazes de realizar análises perceptivas dos usuários em relação ao espaço por ele utilizado, como questionários e experimentos efetuados a partir da utilização de diferentes tipos de iluminação no ambiente.

Por fim, na etapa destinada ao pesquisador foram cruzadas todas as informações obtidas a partir do resultado da pesquisa a fim de desenvolver o diagnóstico. Com isso, obtêmse as recomendações, cujo fundamento é indicar meios que possam servir de solução para os aspectos abordados e verificados ao longo da pesquisa.

Para uma melhor abrangência do resultado a ser obtido, foram escolhidas duas salas com funções e composições diferentes, uma de terapia ocupacional (uma atividade de saúde prestadora de serviços na melhoria do desempenho funcional do paciente), onde serão avaliados os pacientes com atrofias neurológicas e uma sala de fisioterapia, onde são atendidas pessoas sem dificuldades cognitivas e que, em sua grande maioria, recebem atenção temporária ou tratamentos para dores crônicas.

Esse confrontamento de perspectivas surgiu da necessidade de obter resultados que pudessem abranger respostas baseadas tanto na percepção e sensibilidade do paciente cognitivo - por inúmeras vezes expressas em gestos e olhares - como também na objetividade e funcionalidade do paciente sem deficiência, dessa forma, consegue-se uma visão global do mesmo ambiente a partir de visões praticamente opostas.

\section{ANÁLISE GLOBAL DO AMBIENTE}

A instituição assistencial de saúde escolhida como estudo de caso para a presente pesquisa encontra-se localizada, desde agosto de 1987, no mesmo endereço, na cidade do Recife, contando com administração familiar e composta por quatro sócios, tendo como atividade econômica principal a Fisioterapia.

Figura 1: Fachada principal e acesso da clínica

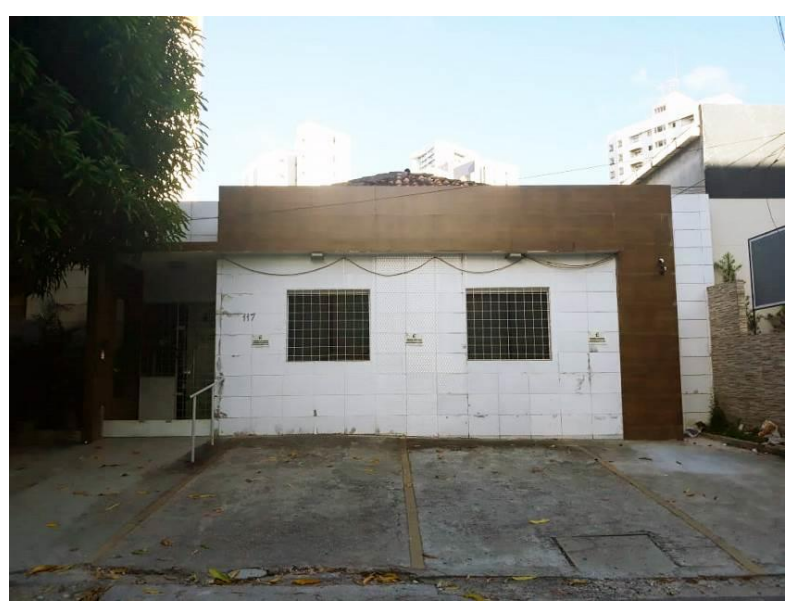

Fonte: autoras (2019) 
O edifício, previamente construído para uso residencial, possui características mistas, dadas as diversas modificações e adaptações feitas ao longo dessas três décadas de atividade. Ao todo são 8 salas de terapia (sendo uma delas para pilates), totalizando uma área construída de $256,13 \mathrm{~m}^{2}$, atendendo um total mensal médio de 60 pacientes distribuídos entre seus 12 terapeutas, em sessões fixas de 30 minutos cada, dentro do horário de funcionamento das $07 \mathrm{~h}$ às 19h30, contando ainda com 2 funcionárias para as funções administrativas.

Tabela 1: Espaços componentes do estabelecimento e suas funções

\begin{tabular}{|c|c|c|c|}
\hline Tipo & Quantidade & Profissionais & Observações \\
\hline Recepção & 01 & 02 Recepcionistas & Atividades administrativas. \\
\hline Espera & 02 & - & Acomodação dos acompanhantes. \\
\hline Consultórios & 08 & $\begin{array}{c}06 \text { Fisioterapeutas } \\
01 \text { Terapeuta } \\
\text { Ocupacional } \\
02 \text { Fonoaudiólogas } \\
02 \text { Psicopedagogas }\end{array}$ & $\begin{array}{l}\text { Atendimento dos pacientes. } \\
\text { Os profissionais revezam algumas salas, pois } \\
\text { atendem em horários alternados. }\end{array}$ \\
\hline Copa & 01 & - & Uso exclusivo dos funcionários. \\
\hline Banheiros & 02 & - & Mistos e acessíveis ao público PNE. \\
\hline Piscina & 01 & 01 Fisioterapeuta & Tratamentos hidroterapêuticos. \\
\hline
\end{tabular}

Fonte: autoras (2019)

Os espaços foram propostos nas adaptações realizadas como melhoramento para as necessidades apresentadas pelos funcionários e terapeutas, além de conectar os elementos normativos surgidos ao longo dos anos, como a acessibilidade, a fim de proporcionar um melhor conforto para os usuários do espaço. Para isso, foi necessário ampliar algumas áreas e facilitar o acesso a todas elas (Figura 2).

O objeto de estudo é classificado como um "Estabelecimento Assistencial de Saúde EAS, denominação dada a qualquer edificação destinada à prestação de assistência à saúde à população, que demande o acesso de pacientes, em regime de internação ou não, qualquer que seja o seu nível de complexidade". (RDC 50, 2002, p.137)

Segundo a ANVISA, essa Resolução trata sobre o "Regulamento Técnico para planejamento, programação, elaboração e avaliação de projetos físicos de estabelecimentos assistenciais de saúde". (RDC 50, 2002, p.1)

De acordo com a norma, as unidades destinadas ao tratamento fisioterapêutico devem ter $2,40 \mathrm{~m}^{2}$, sendo a dimensão mínima de $1,20 \mathrm{~m}$. Essa configuração é especificada para boxes de atendimento e indica que ao menos um deles deve apresentar $1,50 \mathrm{~m}$. No caso da terapia ocupacional o ambiente deve possuir $7,50 \mathrm{~m}^{2}$ e dispor de atendimento individual. Nesses parâmetros, temos uma boa configuração do espaço estudado. 
$17^{\circ}$ ERGODESIGN \& USIHC 2019

PUC-Rio, 11 a 13 de dezembro

Rio de Janeiro, RJ, Brasil $17^{\circ}$ Ergodesign - Congresso Internacional de Ergonomia e Usabilidade de Interfaces Humano Tecnológica: Produto, Informações Ambientes Construídos e Transporte

$17^{\circ}$ USIHC - Congresso Internacional de Ergonomia e Usabilidade de Interfaces Humano Computador

Figura 2: Planta Baixa de Zoneamento

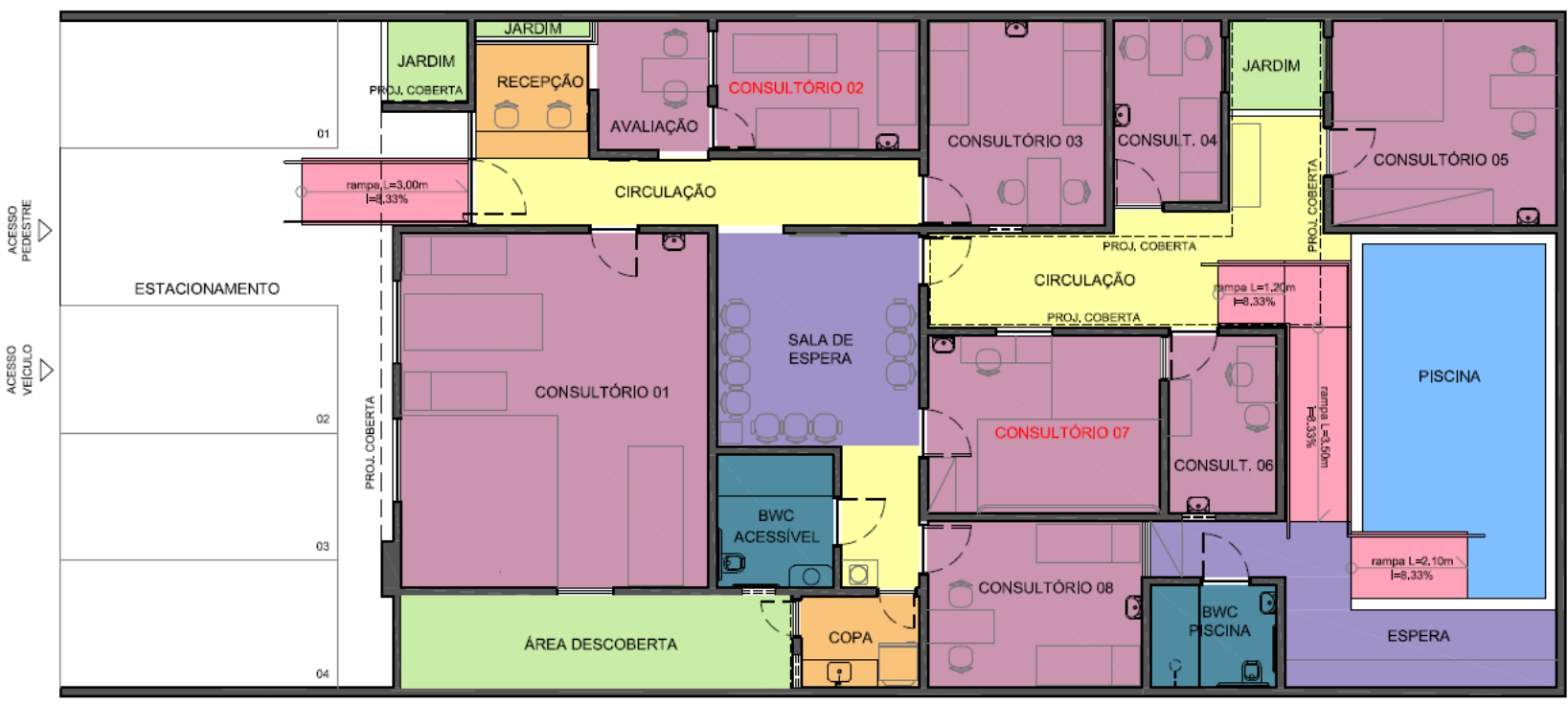

PLANTA BAIXA ZONEAMENTO

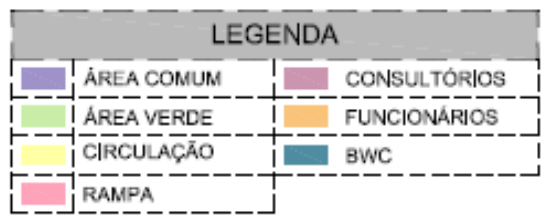

Fonte: autoras (2019)

Desde sua criação, a instituição propõe a associação de diversos profissionais de saúde que possam integrar seus conhecimentos e desenvolver um trabalho em conjunto uns com os outros. Assim, os pacientes usufruem de todo o tratamento terapêutico sem sair do espaço.

Desde então, a clínica trabalha com profissionais de psicologia, fonoaudiologia, terapia ocupacional e fisioterapia, estes, ramificados em áreas como traumatologia, reumatologia, geriatria, pilates, osteopatia, reeducação postural global (RPG), acupuntura, hidroterapia e neuropediatria, sendo esta a especialidade exercida pela sócia majoritária e fundadora do estabelecimento.

O objetivo idealizado em sua fundação foi disponibilizar atendimento de qualidade, a qualquer faixa etária e em diversos setores patológicos, a fim de promover uma recuperação total aos seus pacientes. Nos casos crônicos, a cura pode não ser alcançada como meta real, no entanto, é a partir da experiência dos profissionais que esses pacientes apresentam um incremento em sua qualidade de vida, chegando a atingir objetivos que antes seriam até mesmo irreais para sua malformação.

Em se tratando de atividade, a especialidade e, por consequência, a maior parte de seus atendimentos são percebidas nos pacientes infanto-juvenis diagnosticados com distúrbios neurológicos, podendo permanecer no quadro de clientes por anos consecutivos, sem que isso represente uma diferença em sua estrutura fundamental. Os pais, normalmente inexperientes no assunto, esperam uma alta temporal, o que por diversas vezes não pode ser obtida. Apesar 
da responsabilidade no assunto, a proprietária vê esses pacientes como o coração da instituição, dando aos mesmos total atenção e estímulo.

\subsection{Análise Global da Sala de Terapia Ocupacional}

Dispondo de uma área de $13,44 \mathrm{~m}^{2}$, a primeira sala selecionada apresenta uma utilização mista servindo de apoio a algumas atividades interdisciplinares, em contrapartida, assume a característica de atendimento para a única profissional de Terapia Ocupacional da instituição. Por apresentar uma perspectiva mais voltada para uma estimulação cognitiva, ela mostra mais dinamicidade na composição formal do espaço.

Figura 3: Planta Baixa Consultório 07

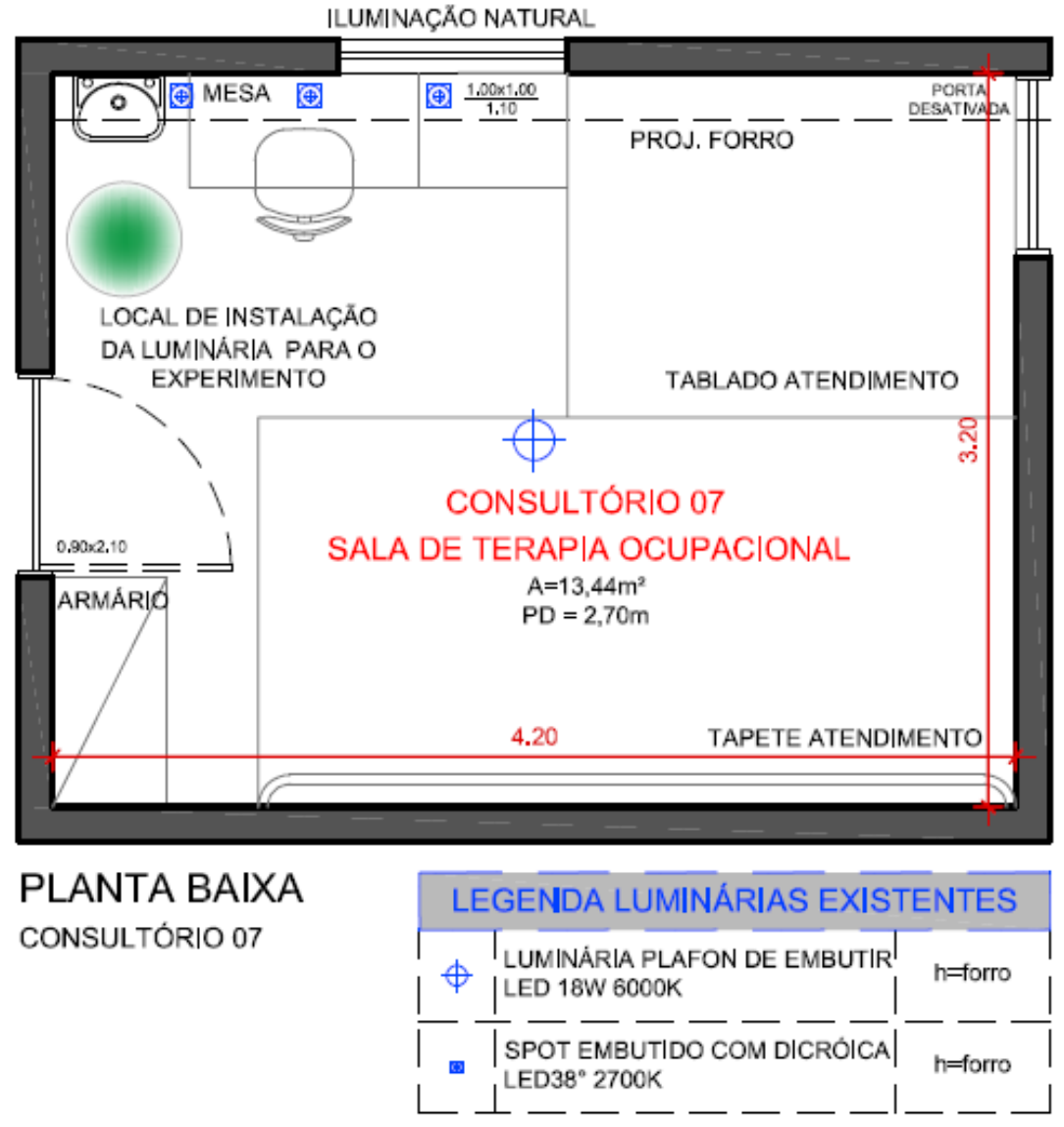

Fonte: autoras (2019)

Considerando o experimento a ser realizado, é apontado na planta da sala o local previsto para instalação da iluminação que servirá de avaliação na reação dos pacientes. 
$17^{\circ}$ ERGODESIGN \& USIHC 2019

PUC-Rio, 11 a 13 de dezembro

Rio de Janeiro, RJ, Brasil $17^{\circ}$ Ergodesign - Congresso Internacional de Ergonomia e Usabilidade de Interfaces Humano Tecnológica: Produto, Informações Ambientes Construídos e Transporte

$17^{\circ}$ USIHC - Congresso Internacional de Ergonomia e Usabilidade de Interfaces Humano Computador

Figuras 4 e 5: Visão geral da sala de Terapia Ocupacional - Consultório 07
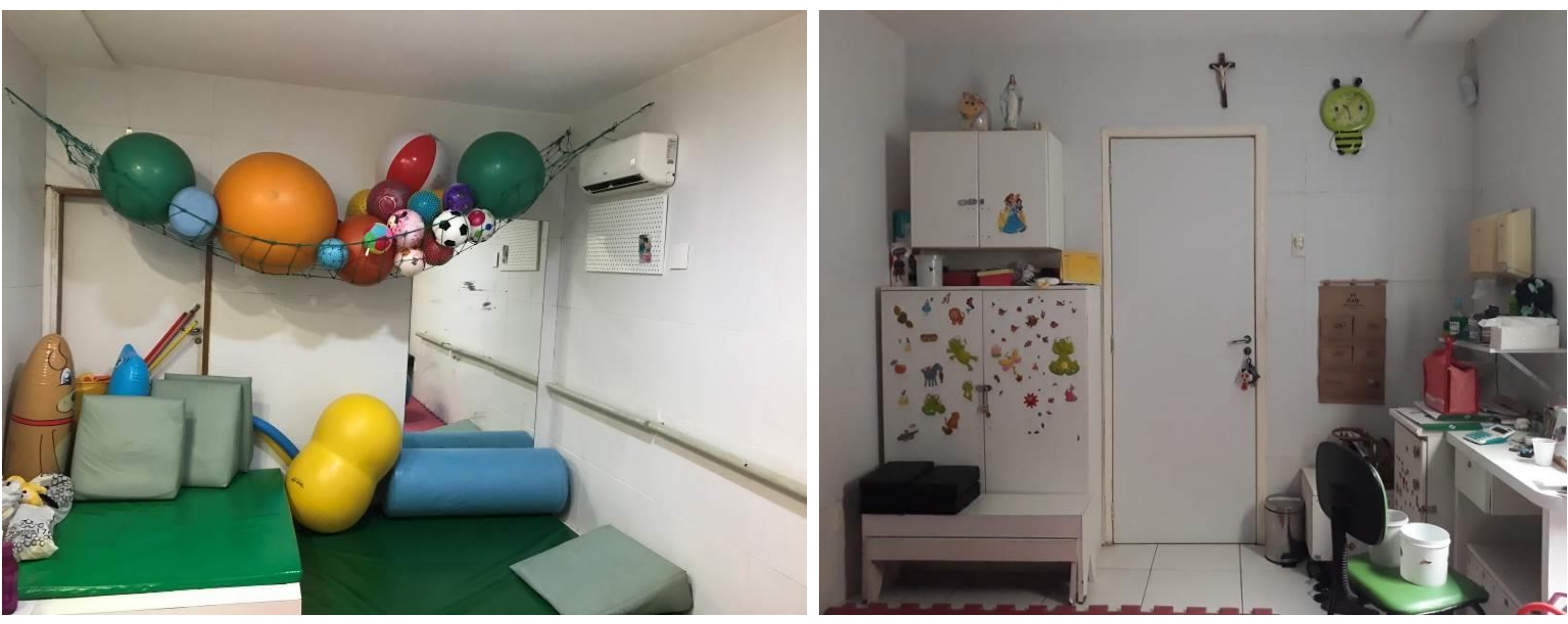

Fonte: autoras (2019)

Nesta sala, chegam a trabalhar simultaneamente até três profissionais, mas apenas em caso de necessidade. Normalmente, a terapeuta usufrui de todo o ambiente, devido à compatibilização das agendas com os demais colegas de trabalho.

Uma relevância apresentada neste consultório é a existência de uma janela, voltada para o pátio de circulação, que permite a entrada da luz natural, característica quase sempre ausente nas áreas de atendimento. Analisando esse fator, pode-se perceber um favoritismo por meio dos profissionais na disputa pelo uso deste espaço.

\subsubsection{Identificação da Configuração Ambiental}

Esta etapa concentrou maior atenção nas condições de luminosidade do ambiente, em função do foco atribuído ao trabalho, não deixando no entanto de observar outras características.

Para a análise do conforto lumínico, foram realizadas quatro medições com o Luxímetro Digital KR812 Akrom (de utilização particular), uma no turno da manhã - $11 \mathrm{~h}$ - e uma à tarde 16h, duas em cada um dos dois pontos selecionados: P01 no ponto mais distante da entrada, no fundo da sala, e P02 próximo a janela.

Os resultados encontrados foram sintetizados no quadro em sequência e comparados à norma NBR 5.413 (ABNT, 1992).

Tabela 2: Dados de medições para lluminância no Consultório 07, em março de 2019

\begin{tabular}{|c||c|c|c|c||}
\hline Ponto & Iluminância 11h & Iluminância 16h & NBR 5.413 & Conclusão \\
\hline P01 & 60 lux & 215 lux & 150-200-300 lux & $\begin{array}{c}\text { A iluminação natural é mais } \\
\text { explorada durante o período diurno, } \\
\text { por isso a diferença de valores maior } \\
\text { no período vespertino. }\end{array}$ \\
\hline P02 & 75 lux & 240 lux & $150-200-300$ lux & $\begin{array}{c}\text { O P02 ficava mais próximo da janela, } \\
\text { captando um pouco mais da } \\
\text { interferência da iluminação natural. }\end{array}$ \\
\hline
\end{tabular}


$17^{\circ}$ ERGODESIGN \& USIHC 2019

PUC-Rio, 11 a 13 de dezembro

Rio de Janeiro, RJ, Brasil $17^{\circ}$ Ergodesign - Congresso Internacional de Ergonomia e Usabilidade de Interfaces Humano Tecnológica: Produto, Informações Ambientes Construídos e Transporte

$17^{\circ}$ USIHC - Congresso Internacional de Ergonomia e Usabilidade de Interfaces Humano Computador

Concluindo, a partir do cruzamento das informações, obteve-se as reais necessidades e deficiências apresentadas por cada uma das salas, sendo elas diretamente influenciadas pela ausência ou existência da iluminação natural direta. Item que colabora com a salubridade do espaço e do próprio ser humano.

O revestimento da sala é em cerâmica, até a altura de $1,50 \mathrm{~m}$, e com pintura em tinta acrílica fosca branca na altura restante das paredes. Os móveis são revestidos de fórmica branca, destacando as cores observadas nos brinquedos e equipamentos utilizados na terapia.

O ambiente é acessível aos usuários de cadeira de rodas e dotado de equipamentos de apoio para o tratamento de disfunções motoras. O conforto térmico é proporcionado pelo ar condicionado que fica sempre ligado durante o funcionamento do espaço. Já em termos acústicos foram observadas falhas na absorção do som que vem da sala de espera.

\subsection{Análise Global da Sala de Fisioterapia}

Comparativamente ao ambiente anterior, a sala dispõe de $8,57 \mathrm{~m}^{2}$, bem menor fisicamente falando, mas o problema é imensamente agravado quando observada a disposição das macas no espaço indicado. Toda amplitude e estimulação percebidos na sala de Terapia Ocupacional são vastamente eliminados, principalmente, graças a característica principal encontrada nos usuários desta área: a efemeridade do tratamento.

Figura 6: Planta Baixa Consultório 02
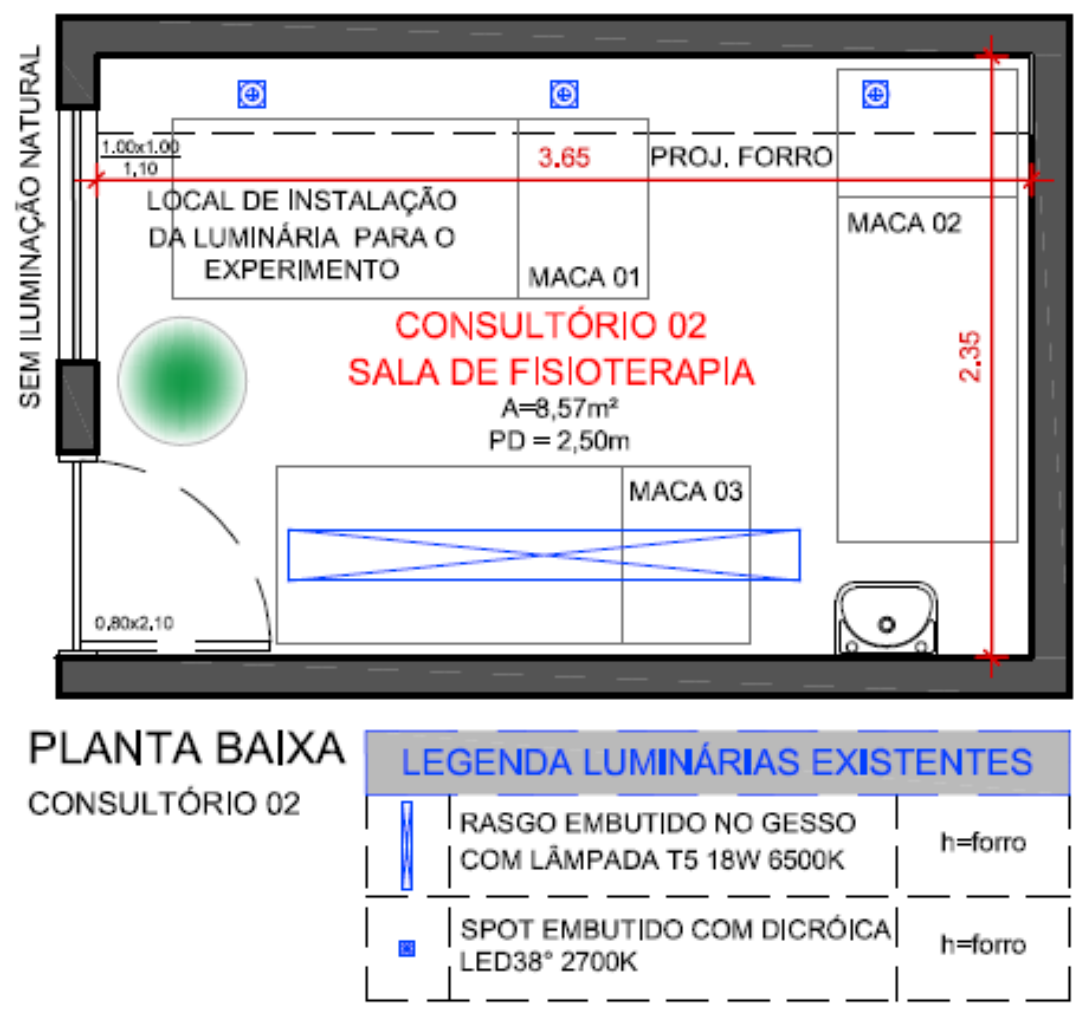

Fonte: autoras (2019) 
Com um tratamento imediato e de retorno financeiro mais dinâmico, a sala foi prevista para o atendimento simultâneo de até três pacientes, pelo mesmo profissional. Com isso, 0 espaço de circulação existe apenas para a locomoção do fisioterapeuta, a fim de permitir a instalação e o manuseio dos equipamentos voltados aos tratamentos mecânicos que atuam no limiar da dor para a recuperação de lesões ou redução de desconfortos crônicos.

Nesta sala, a janela existente é voltada para a área de avaliação, impossibilitando a entrada de luz natural no ambiente. Como o atendimento desses pacientes possui um tempo mais curto e normalmente associado a apenas algumas sessões (exceto nos casos de dores crônicas, onde é aconselhável o acompanhamento de um profissional por todo o tempo, evitando crises e reincidências pontuais), nenhum deles apresentou desconforto em relação a ausência da visibilidade externa.

Embora todos tenham mostrado um certo desconforto quando necessário compartilhar o profissional com outros dois pacientes (muitas vezes desconhecidos e sem qualquer intimidade). Ainda assim, a sala costuma se manter sempre em sua capacidade máxima.

Figuras 7 e 8: Visão geral da sala de Fisioterapia - Consultório 02
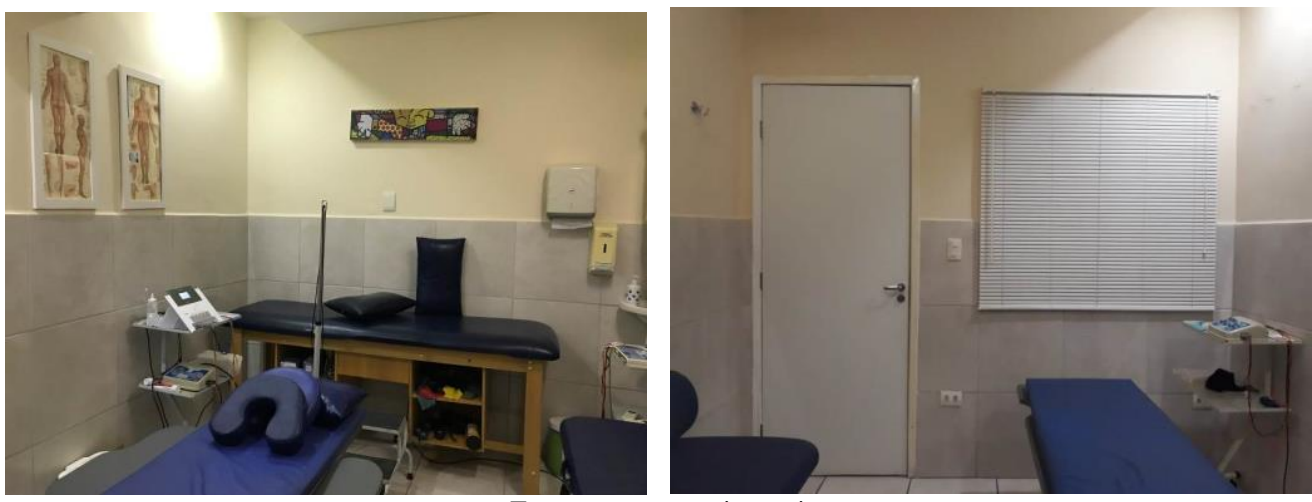

Fonte: autoras (2019)

\subsubsection{Identificação da Configuração Ambiental}

Para a análise do conforto lumínico, foram realizadas quatro medições com o Luxímetro Digital KR812 Akrom (de utilização particular), uma no turno da manhã - 11h - e uma à tarde 16h, duas em cada um dos dois pontos selecionados: P03 no ponto mais distante da entrada, no fundo da sala, e P04 próximo a janela.

Tabela 3: Dados de medições para lluminância no Consultório 02, em março de 2019

\begin{tabular}{|c|c|c||c|c||}
\hline Ponto & Iluminância 11h & Iluminância 16h & NBR5.413 & Conclusão \\
\hline 03 & 60 lux & 215 lux & $150-200-300$ lux & $\begin{array}{c}\text { Não é iluminação natural por isso } \\
\text { quase não há diferença de valores } \\
\text { nos períodos. }\end{array}$ \\
\hline 04 & 75 lux & 240 lux & $150-200-300$ lux & $\begin{array}{c}\text { O P04, mais próximo da janela, teve } \\
\text { uma diferença mínima de valores. }\end{array}$ \\
\hline
\end{tabular}

Os resultados encontrados foram sintetizados na tabela 3 e comparados à norma NBR 5.413 (ABNT, 1992). 


\section{$17^{\circ}$ ERGODESIGN \& USIHC 2019}

PUC-Rio, 11 a 13 de dezembro

Rio de Janeiro, RJ, Brasil $17^{\circ}$ Ergodesign - Congresso Internacional de Ergonomia e Usabilidade de Interfaces Humano Tecnológica: Produto, Informações Ambientes Construídos e Transporte

$17^{\circ}$ USIHC - Congresso Internacional de Ergonomia e Usabilidade

de Interfaces Humano Computador

O revestimento da sala é em cerâmica, até a altura de $1,50 \mathrm{~m}$, e pintura em tinta acrílica fosca bege na altura restante das paredes. Os móveis são metálicos para suporte dos equipamentos, destacando a ausência de estimulações visuais de cores.

O ambiente não é acessível aos usuários de cadeira de rodas devido às suas dimensões. O conforto térmico é proporcionado pelo ar condicionado que fica sempre ligado durante o funcionamento do espaço. Diferentemente da sala anterior não foram observadas falhas significativas na absorção do som de outros ambientes.

\section{AVALIAÇÃO DO AMBIENTE EM USO}

Após várias mudanças na configuração espacial, o estabelecimento passou a atender as normas de acessibilidade de forma satisfatória, aumentando os espaços de circulação e permitindo um fluxo maior de pessoas sem pontos de interrupção. Os pacientes e funcionários são recepcionados pela mesma entrada e se deslocam até a sala de espera, de onde são distribuídos conforme seus atendimentos diários.

Figura 9: Planta Baixa Fluxo de Circulação

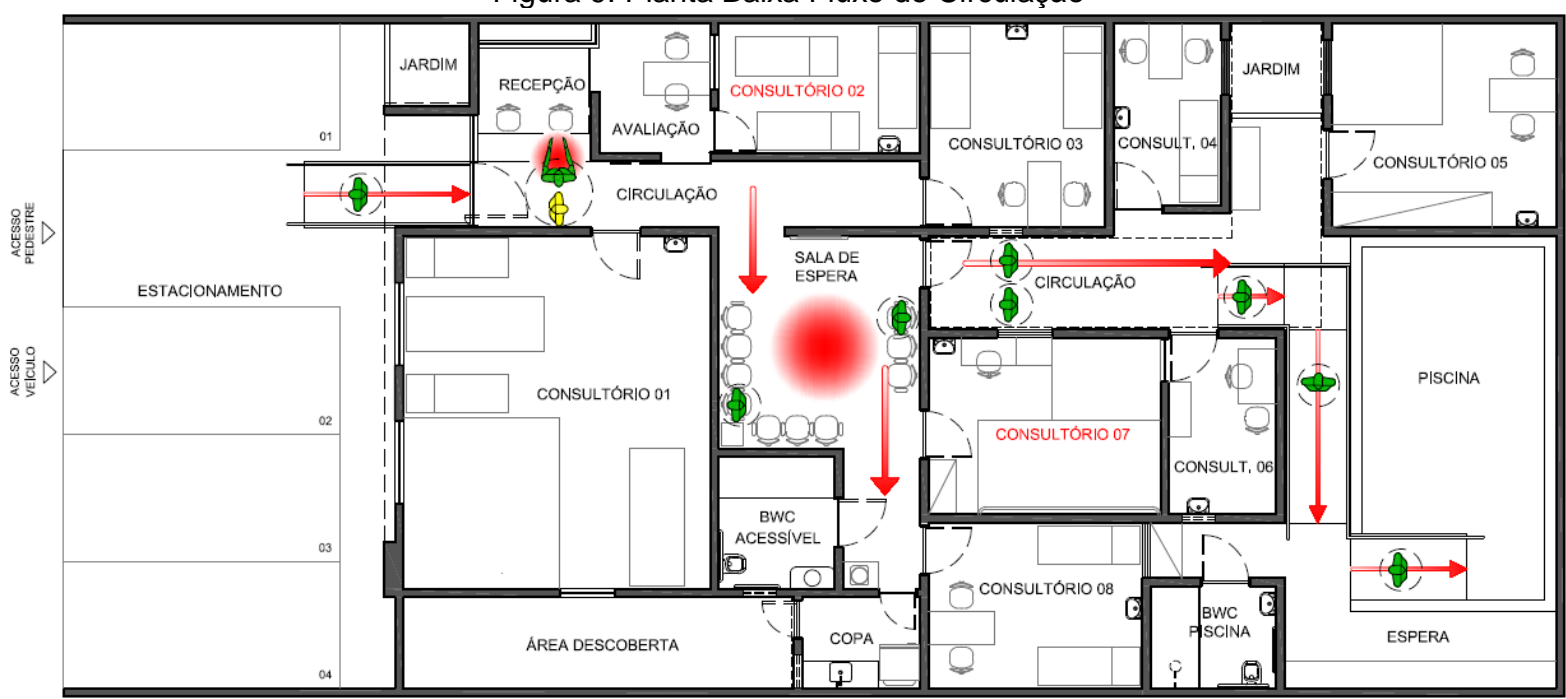

PLANTA BAIXA

FLUXO CIRCULAÇÃO

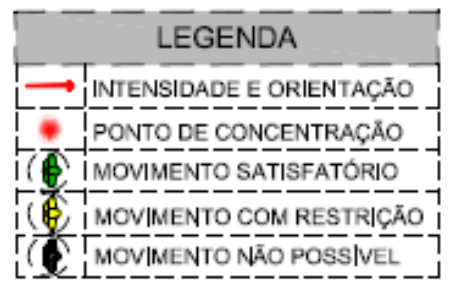

Fonte: autoras (2019)

\section{ANÁLISE DA PERCEPÇÃO DO USUÁRIO}

Foram selecionados ao todo 20 pacientes, $10 \mathrm{em}$ cada sala, para participarem da análise do ambiente através de um experimento lumínico. Os questionários aplicados, 
formatados exclusivamente para apresentar a percepção da luz, foram aplicados em dois momentos. No primeiro, funcionavam como uma entrevista, que definia se a iluminação atual causava algum transtorno, ou simplesmente não havia sido observada. Em seguida, os usuários permaneciam em atendimento e era instalada uma luminária que deveria gerar emoções nos mesmos.

Todos os voluntários assinaram termos onde foram alertados de que não seriam nomeados, mas suas sensações serviriam de parâmetro para a síntese e conclusão do experimento. Além do termo de autorização, assinado pela fundadora da instituição, que permitiu a execução das atividades.

Figuras 10 e 11: Questionários aplicados aos pacientes antes e após o experimento

QUESTIONÁRIO INICIAL

\begin{tabular}{|c|c|c|}
\hline \multicolumn{3}{|l|}{ PACIENTE No - } \\
\hline \multicolumn{3}{|l|}{ 1-SEXO DO PACIENTE } \\
\hline () FEMININO & () MASCULINO & \\
\hline \multicolumn{3}{|l|}{2 -IDADE DO PACIENTE } \\
\hline () ENTRE OE 5 ANOS & () ENTRE 5 E 10 ANOS & () ACIMA DE 10 ANOS \\
\hline \multicolumn{3}{|c|}{3 - NECESSIDADE DO PACIENTE } \\
\hline ( ) COGNITIVA & ( ) MOTORA & () AMBAS \\
\hline \multicolumn{3}{|c|}{4 - PERCEPÇÃo dA LUZ NATURAL NO AMBIENTE } \\
\hline () SUFICIENTE & ( ) NORMAL & () POUCA \\
\hline \multicolumn{3}{|c|}{5 - PERCEPÇÃO DA LUZ ARTIFICIAL NO AMBIENTE } \\
\hline () SUFIIENTE & () NORMAL & (1) POUCA \\
\hline \multicolumn{3}{|c|}{ 6-A LUZ ATUAL INFLUENCIA NO COMPORTAMENTO DO PACIENTE? } \\
\hline ( ) $\sin$ & ( ) NÃO & () NUNCA NOTEI \\
\hline \multicolumn{3}{|c|}{$\begin{array}{l}\text { 7-ALGUMAVEZ O PACIENTE SE QUEIXOU DE INCÔMODOS COMO DOR DE CABEÇA, IRRTIABILIDADE, } \\
\text { ANSIEDADE, OU OUTROS, PóS ATENDIMENTO NESTA SALA? }\end{array}$} \\
\hline ( ) $\sin$ & ( ) NÃO & () NUNCA NOTEI \\
\hline \multicolumn{3}{|c|}{ OBSERVAÇŐ̈ES PESSOAIS SOBRE A ALUMINAÇ̄̃o DA SALA: } \\
\hline
\end{tabular}

QUESTIONÁRIO PÓS-EXPERIMENTOS

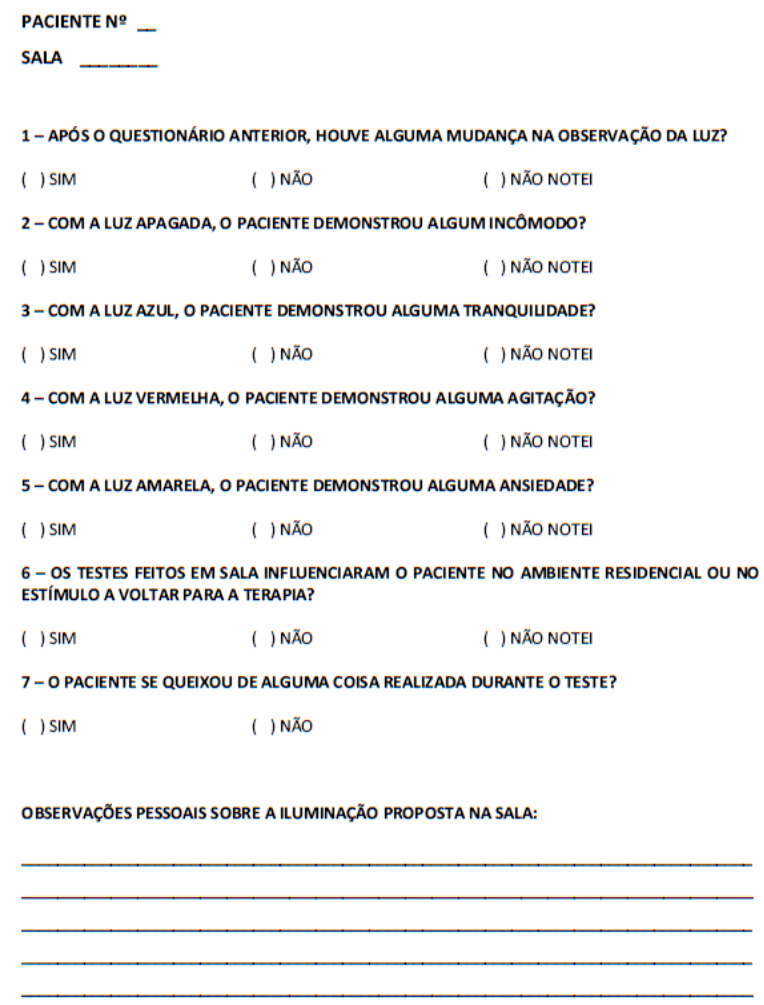

Fonte: autoras (2019)

Foram selecionados pacientes que melhor caracterizassem cada sala e a atividade nela desenvolvida. Dessa forma, para a realização dos testes, utilizaram-se 10 pacientes com dificuldades cognitivas em atendimento na sala de Terapia Ocupacional e 10 pacientes sem nenhuma deficiência, apenas problemas pontuais motores. Ao cruzar as duas formas de percepção, pode-se obter um resultado mais completo e fiel às respostas apresentadas.

O teste aplicado especificamente a partir da instalação da luminária consistia em 4 etapas. Nas 3 primeiras, o paciente identificava a sua relação sensorial de acordo com a cor que dominava o ambiente através de lâmpadas acesas com filtros vermelho, amarelo e azul. Por último, a luz inteira da sala era apagada e novamente o usuário determinava sua sensação. 
Todas as reações foram pautadas em uma hipótese de tratamento submetido àquele tipo de luz que estava sendo apresentada. Os pacientes com dificuldade de interação eram acompanhados pelos pais que identificavam suas reações através de suas expressões. Os testes seguiram durante uma semana, com horários diversificados, no mês de maio de 2019.

Figuras 12, 13 e 14: Luminária utilizada durante o experimento, com suas respectivas cores
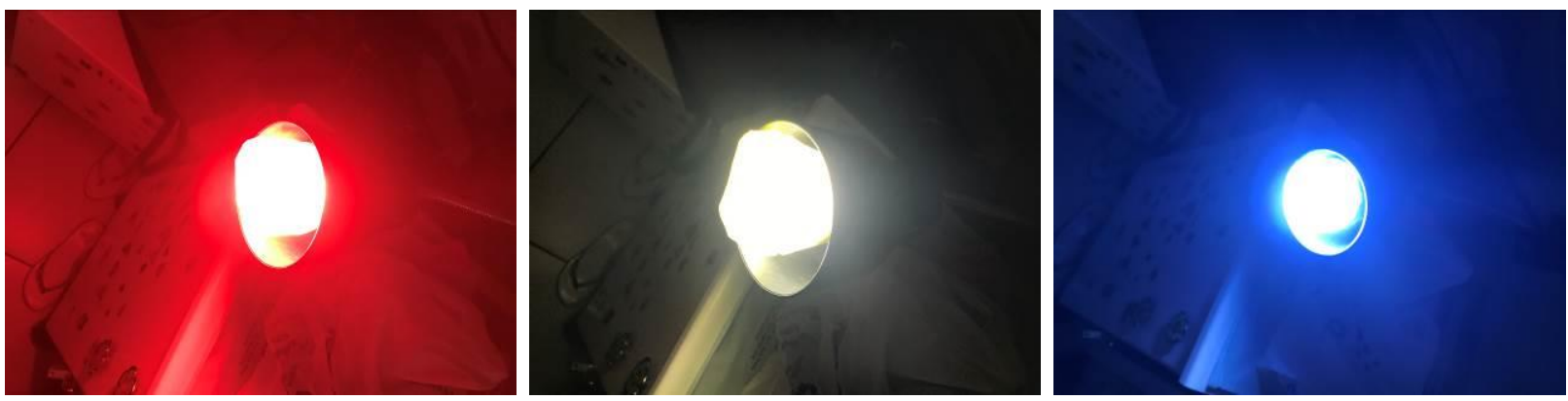

Fonte: autoras (2019)

\subsection{Percepção do usuário na sala de Terapia Ocupacional}

Figuras 15, 16 e 17: Imagens durante o experimento, com suas respectivas cores, sala de T.O.
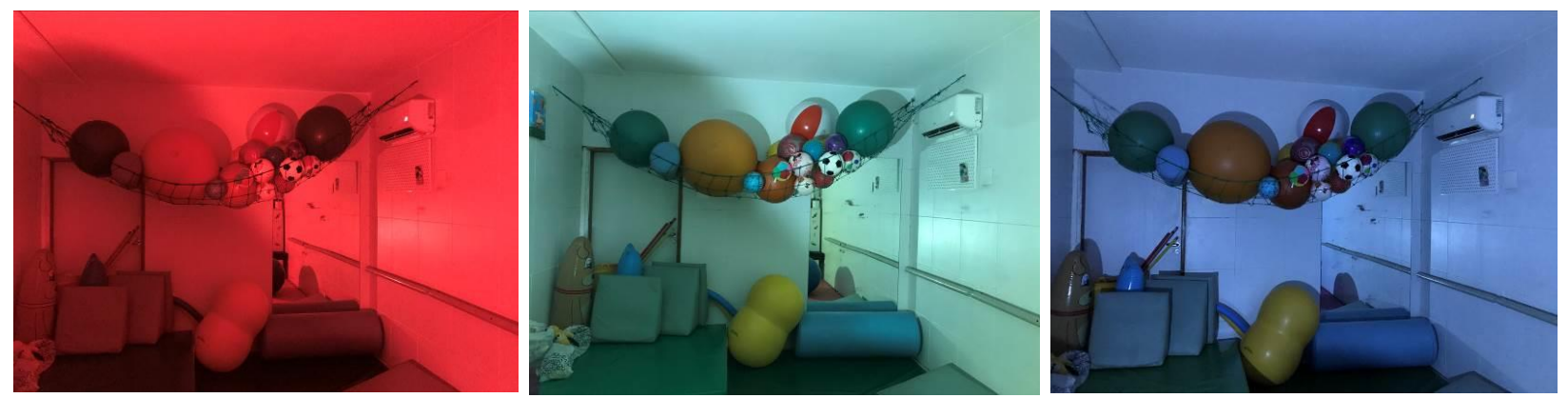

Fonte: autoras (2019)

Como sintetização dos resultados apresentados, foram elaborados as tabelas com as análises da amostragem, os resultados alcançados e as reações de cada paciente.

De modo geral, nenhum dos usuários percebiam a luz previamente no ambiente. E após o experimento passaram a observá-la de maneira diferente. Apenas os pacientes 03, 04, 07 e 08 precisaram de interpretação dos pais nas respostas fornecidas.

Quase que totalmente todos os usuários demonstraram algum desconforto com a ausência total de luz, ainda que houvesse alguma iluminação natural no ambiente. Apenas o 09 não demonstrou nenhum incômodo e permaneceu fazendo suas atividades.

Já a luz azul obteve quase que total preferência entre os pacientes, sendo sempre relacionada com tranquilidade. Em contraposição, a luz vermelha foi apresentada como inquietação e aceita quase que por completo em pacientes com alguma dificuldade visual. 


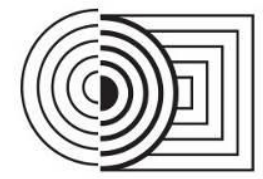

$17^{\circ}$ ERGODESIGN \& USIHC 2019

PUC-Rio, 11 a 13 de dezembro

Rio de Janeiro, RJ, Brasil $17^{\circ}$ Ergodesign - Congresso Internacional de Ergonomia e Usabilidade de Interfaces Humano Tecnológica: Produto, Informações Ambientes Construídos e Transporte

$17^{\circ}$ USIHC - Congresso Internacional de Ergonomia e Usabilidade

de Interfaces Humano Computador

Tabela 4: Síntese dos resultados obtidos na aplicação dos questionários e do experimento

\begin{tabular}{|c|c|c|c|c|c|c|c|c|}
\hline \multicolumn{9}{|c|}{ Experimento realizado na sala de Terapia Ocupacional } \\
\hline \multirow{2}{*}{ ID } & \multirow{2}{*}{$\begin{array}{c}\text { Dificuldade } \\
\text { Cognitiva }\end{array}$} & \multirow{2}{*}{$\begin{array}{l}\text { Idade } \\
\text { (Anos) }\end{array}$} & \multirow{2}{*}{ Sexo } & \multicolumn{5}{|c|}{ Reação do Paciente sobre a Luz } \\
\hline & & & & Atual & Vermelha & Amarela & Azul & Apagada \\
\hline 01 & Alzheimer & 80 & M & $=$ & $\mathrm{X}$ & $\checkmark$ & $\checkmark$ & $X$ \\
\hline 02 & E.L.A. & 17 & $\mathrm{~F}$ & $=$ & $\mathrm{X}$ & $\checkmark$ & $\checkmark$ & $\mathrm{X}$ \\
\hline 03 & $\begin{array}{c}\text { Síndrome de } \\
\text { Down }\end{array}$ & 2 & $\mathrm{~F}$ & $=$ & $\checkmark$ & $=$ & $\sqrt{ }$ & $=$ \\
\hline 04 & Retardo & 22 & M & $=$ & $X$ & $=$ & $\checkmark$ & $X$ \\
\hline 05 & Microcefalia & 4 & $\mathrm{~F}$ & $=$ & $X$ & $\checkmark$ & $\sqrt{ }$ & $X$ \\
\hline 06 & $\begin{array}{l}\text { Paralisia } \\
\text { Cerebral }\end{array}$ & 17 & $\mathrm{~F}$ & $=$ & $X$ & $=$ & $\checkmark$ & $X$ \\
\hline 07 & $\begin{array}{l}\text { Paralisia } \\
\text { Cerebral }\end{array}$ & 22 & $F$ & $=$ & $\checkmark$ & $X$ & $\checkmark$ & $=$ \\
\hline 08 & Hidrocefalia & 2 & $\mathrm{~F}$ & $=$ & $\checkmark$ & $X$ & $=$ & $X$ \\
\hline 09 & Autismo & 3 & M & $=$ & $x$ & $\checkmark$ & $=$ & $\sqrt{ }$ \\
\hline 10 & Autismo & 4 & $M$ & $=$ & $\checkmark$ & $\checkmark$ & $\checkmark$ & $x$ \\
\hline
\end{tabular}

Legenda:

$\checkmark \quad$ Gostam e permaneceriam em um ambiente de tratamento com essa luz.

$=\quad$ Indiferentes à luz no ambiente de tratamento.

$\mathrm{X}$ Detestam e não permaneceriam em um ambiente de tratamento com essa luz.

Fonte: autoras (2019)

\subsection{Percepção do usuário na sala de Fisioterapia}

O experimento foi repetido igualmente ao realizado na sala de terapia ocupacional, sendo os resultados descritos a seguir e apresentados na tabela síntese. 
$17^{\circ}$ ERGODESIGN \& USIHC 2019

PUC-Rio, 11 a 13 de dezembro

Rio de Janeiro, RJ, Brasil $17^{\circ}$ Ergodesign - Congresso Internacional de Ergonomia e Usabilidade de Interfaces Humano Tecnológica: Produto, Informações Ambientes Construídos e Transporte

$17^{\circ}$ USIHC - Congresso Internacional de Ergonomia e Usabilidade de Interfaces Humano Computador

Figuras 18, 19 e 20: Imagens durante o experimento, com suas respectivas cores, sala de Fisioterapia
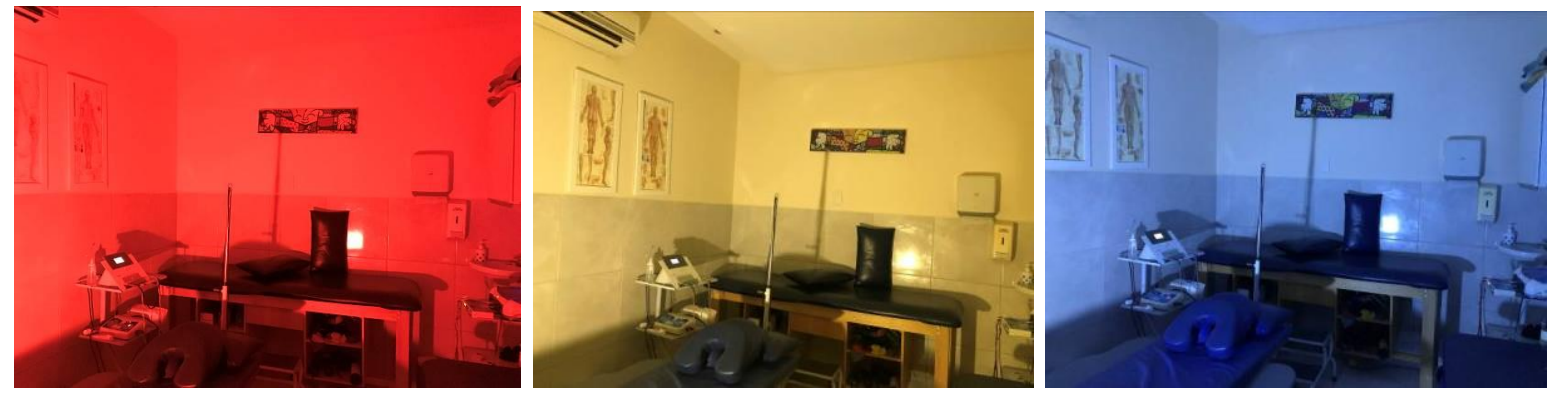

Fonte: autoras (2019)

Tabela 5: Síntese dos resultados obtidos na aplicação dos questionários e do experimento

\begin{tabular}{|c|c|c|c|c|c|c|c|c|}
\hline \multicolumn{9}{|c|}{ Experimento realizado na sala de Fisioterapia } \\
\hline \multirow{2}{*}{ ID } & \multirow{2}{*}{$\begin{array}{l}\text { Tratamento } \\
\text { Motor }\end{array}$} & \multirow{2}{*}{$\begin{array}{l}\text { Idade } \\
\text { (Anos) }\end{array}$} & \multirow{2}{*}{ Sexo } & \multicolumn{5}{|c|}{ Reação do Paciente sobre a Luz } \\
\hline & & & & Atual & Vermelha & Amarela & Azul & Apagada \\
\hline 11 & Lombar & 89 & $\mathrm{~F}$ & $=$ & $\checkmark$ & $=$ & $=$ & $\mathrm{x}$ \\
\hline 12 & Joelho & 82 & $\mathrm{~F}$ & $=$ & $\mathrm{x}$ & $=$ & $\checkmark$ & $\mathrm{x}$ \\
\hline 13 & Cotovelo & 56 & $\mathrm{~F}$ & $=$ & $\checkmark$ & $\mathrm{x}$ & $\checkmark$ & $\mathrm{x}$ \\
\hline 14 & Artrose & 69 & $\mathrm{~F}$ & $=$ & $\mathrm{x}$ & $\mathrm{x}$ & $\checkmark$ & $\checkmark$ \\
\hline 15 & Coluna & 36 & M & $=$ & $\mathrm{x}$ & $\checkmark$ & $\checkmark$ & $\mathrm{x}$ \\
\hline 16 & Joelho & 38 & $\mathrm{~F}$ & $=$ & $\mathrm{x}$ & $\mathrm{x}$ & $\checkmark$ & $\mathrm{x}$ \\
\hline 17 & Tendinite & 38 & $\mathrm{~F}$ & $=$ & $\mathrm{x}$ & $\mathrm{x}$ & $\checkmark$ & $\mathrm{x}$ \\
\hline 18 & Artrite & 65 & $\mathrm{~F}$ & $=$ & $\mathrm{X}$ & $\mathrm{X}$ & $\checkmark$ & $\mathrm{x}$ \\
\hline 19 & Pé & 66 & $\mathrm{~F}$ & $=$ & $x$ & $x$ & $\checkmark$ & $\checkmark$ \\
\hline 20 & Artrose & 60 & $\mathrm{~F}$ & $=$ & $\checkmark$ & $\mathrm{X}$ & $=$ & $\mathrm{x}$ \\
\hline
\end{tabular}

\section{Legenda:}

$\checkmark \quad$ Gostam e permaneceriam em um ambiente de tratamento com essa luz.

$=\quad$ Indiferentes à luz no ambiente de tratamento.

X Detestam e não permaneceriam em um ambiente de tratamento com essa luz. 
$17^{\circ}$ ERGODESIGN

\& USIHC 2019

PUC-Rio, 11 a 13 de dezembro

Rio de Janeiro, RJ, Brasil $17^{\circ}$ Ergodesign - Congresso Internacional de Ergonomia e Usabilidade de Interfaces Humano Tecnológica: Produto, Informações Ambientes Construídos e Transporte

$17^{\circ}$ USIHC - Congresso Internacional de Ergonomia e Usabilidade de Interfaces Humano Computador

Fonte: autoras (2019)

\section{DIAGNÓSTICO}

Foram analisados 20 pacientes de um total de 60 mensais. Essa amostragem representa $33,33 \%$ dos pacientes da instituição.

Gráfico 01: Apresentação da proporção de amostragem em relação ao total de pacientes

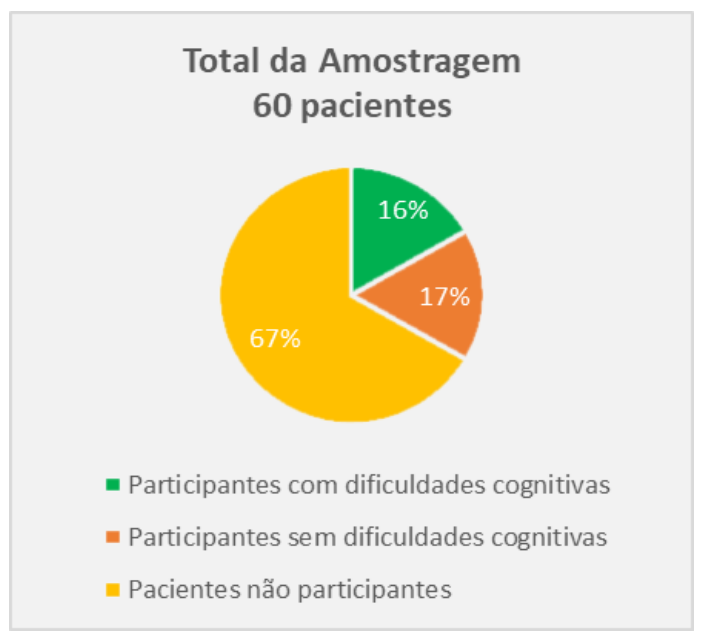

Cruzando informações obtidas pela observação reacionária dos pacientes com os dados provenientes das medições técnicas e normativas, pode-se concluir os seguintes percentuais informados nos gráficos abaixo.

Gráfico 02: Comparativo entre pacientes com e sem dificuldades acerca das luzes preferidas
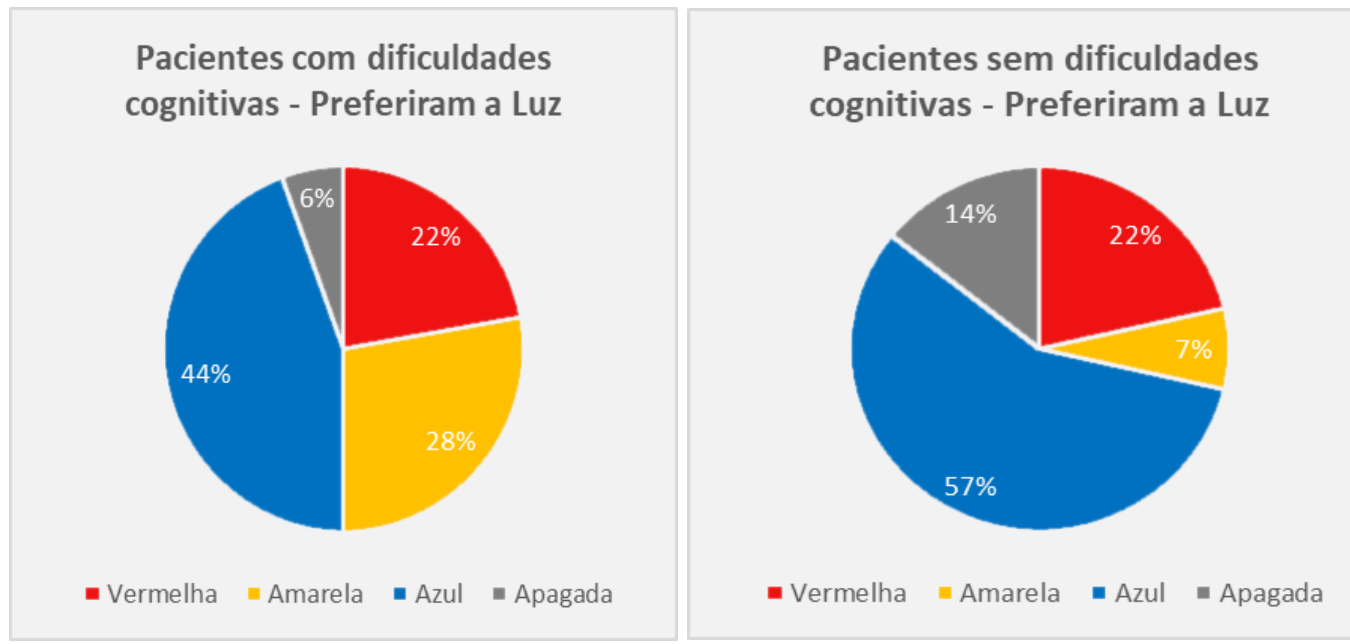
$17^{\circ}$ ERGODESIGN

\& USIHC 2019

PUC-Rio, 11 a 13 de dezembro

Rio de Janeiro, RJ, Brasil $17^{\circ}$ Ergodesign - Congresso Internacional de Ergonomia e Usabilidade de Interfaces Humano Tecnológica: Produto, Informações Ambientes Construídos e Transporte

$17^{\circ}$ USIHC - Congresso Internacional de Ergonomia e Usabilidade de Interfaces Humano Computador

Gráfico 03: Comparativo entre pacientes com e sem dificuldades acerca das luzes indiferentes

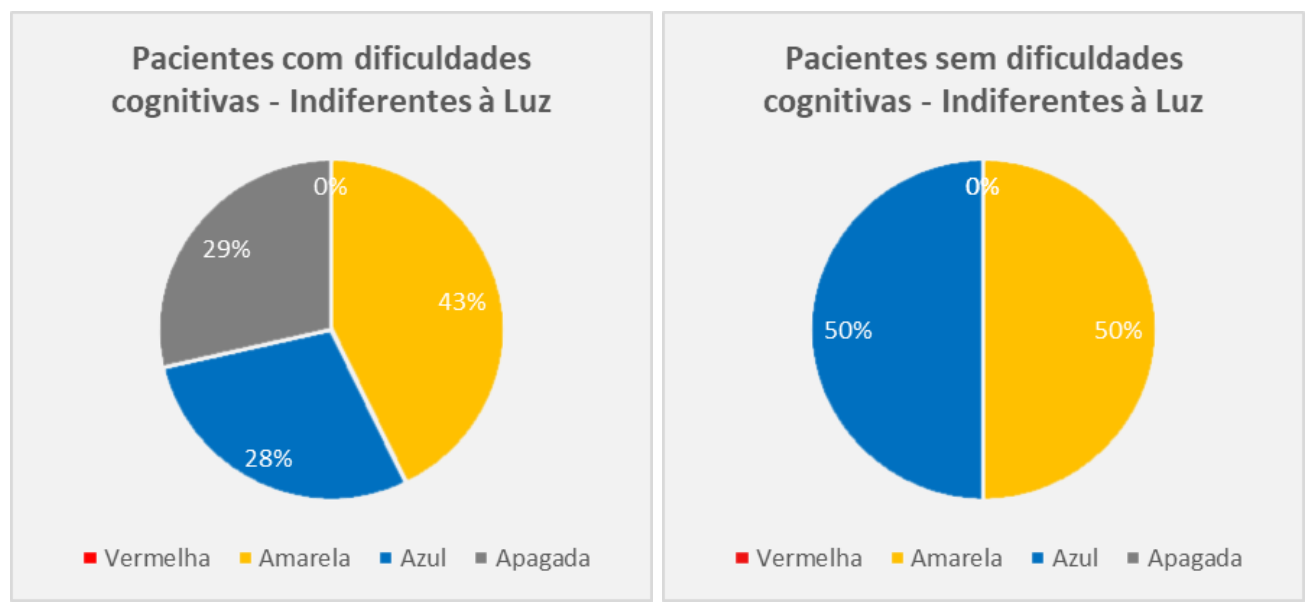

Gráfico 04: Comparativo entre pacientes com e sem dificuldades acerca das luzes detestadas

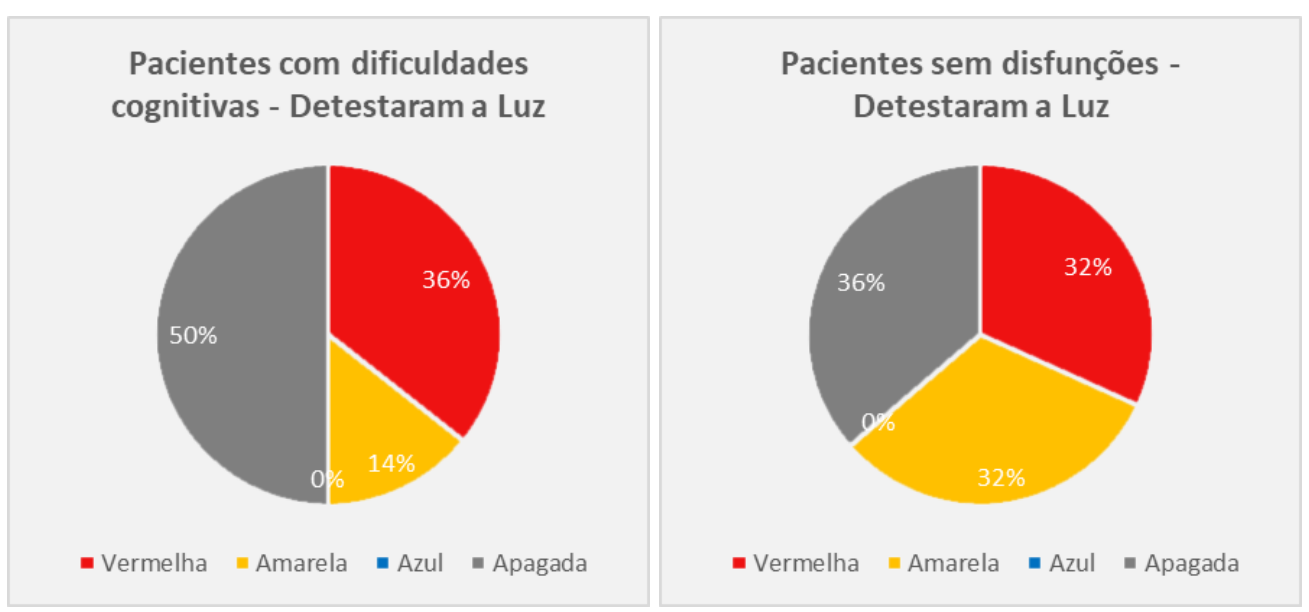

Gráfico 05: Luzes preferidas de todos os pacientes
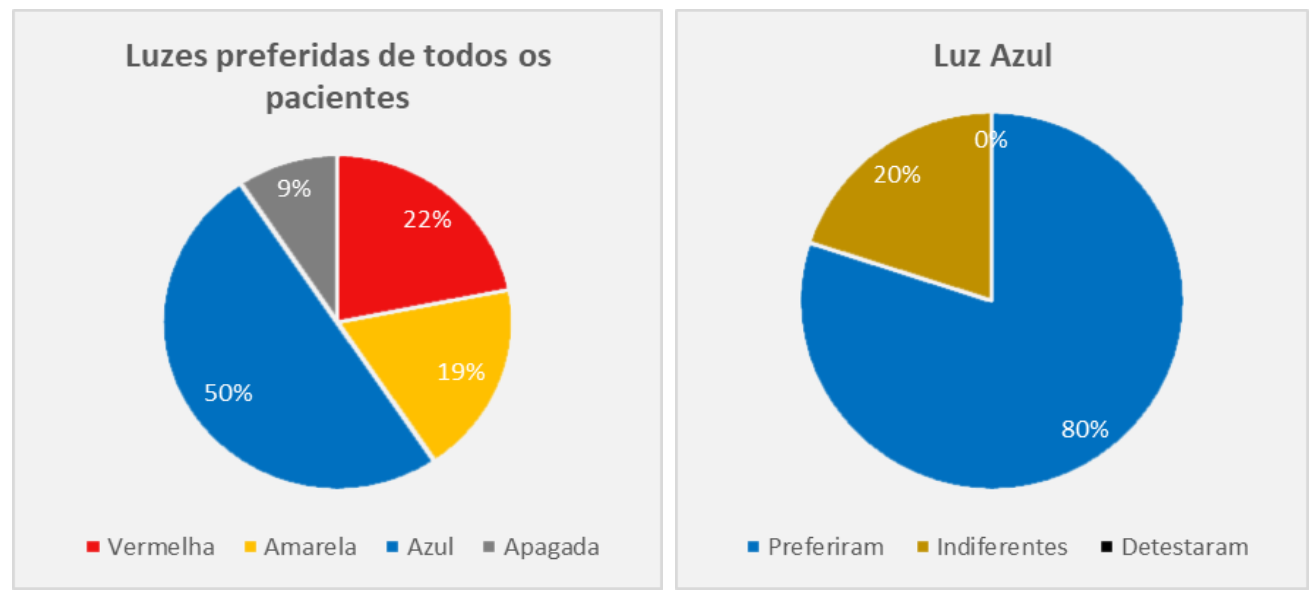
Em se tratando de cores, a percepção pode ser influenciada pela relação afetiva reconhecida através da cor preferida. No entanto, nenhum dos entrevistados detestou a cor azul. Apenas $20 \%$ foram indiferentes, o que relaciona os $80 \%$ restantes com a semântica de que esta coloração traz características de paz e tranquilidade ao ambiente, o que os faria permanecer no mesmo por mais tempo.

As diferenças apresentadas na avaliação dos dois tipos de pacientes foi um fator surpreendente no decorrer da atividade. Era critério inicial, a ideia de que os portadores de dificuldades de compreensão não demonstrariam interesse pelas luzes. O paradigma foi quebrado completamente e foram eles que demonstraram maior interesse e perspicácia durante a implementação do teste.

\section{RECOMENDAÇÕES}

A fim de expandir os resultados positivos obtidos através do estudo, tem-se como principal ponto de partida uma indicação de luzes mais suaves que proporcionem aconchego aos pacientes durante o tratamento. Elas são encontradas nas salas estudas, mas funcionam apenas como elemento decorativo, uma vez que dificilmente são acionadas.

Os pacientes com transtorno do espectro autista demonstraram uma surpresa no experimento, por isso se faria necessário um estudo mais aprofundado acerca do alcance de seu tratamento, visto que acentuaram sua atenção nos momentos onde foi utilizada a cor vermelha, se tornando, em consequência, mais calmos.

No caso dos pacientes com comportamento mais agitado, por consequências de sua deficiência, o ideal seria implementar luzes com filtros azuis para que os mesmos pudessem colaborar de forma mais determinada durante sua sessão de atividade. Já no caso dos pacientes sem disfunções, a utilização da cor azul traria os mesmos resultados. A adoção dela para os ambientes dependeria da necessidade de participação deles ao tratamento. O quanto dependeria dele o estímulo gerado pela iluminação.

\section{CONSIDERAÇÕES FINAIS}

A iluminação traz benefícios reais à saúde humana. Além de ser alvo de diversas pesquisas que comprovam o seu efetivo beneficiamento para a estimulação do recebimento de informações por meio da atividade cerebral. Ou seja, quando corretamente estudada, executada e explorada, a luz pode servir como potencializadora do exercício praticado.

De maneira inicial, o estudo indica parâmetros replicáveis em outras instituições, mas é através de seus dados específicos que se obtém uma real informação acerca da necessidade de implementação de estudos lumínicos intensificando os resultados nas áreas abordadas.

A presente pesquisa indicou, através de estimulações luminotécnicas e avaliações do ambiente construído, que esta relação de melhoria pode também ser relacionada à estabelecimentos assistenciais de saúde, alcançando objetivos extremamente positivos, principalmente nos locais de atendimento a pessoas com deficiência.

O estudo insere-se nos domínios da ergonomia do ambiente construído, quando estabelece relações entre atributos do ambiente construído e as reações humanas quando pessoas são expostas a eles. As cores na iluminação transformando os espaços pode ser melhor explorada a partir da ampliação a outros ambientes de atenção à saúde, ou de trabalho. 


\section{REFERÊNCIAS}

AGÊNCIA NACIONAL DE VIGILÂNCIA SANITÁRIA. RDC 50: Regulamento Técnico para planejamento, programação, elaboração e avaliação de projetos físicos de estabelecimentos assistenciais de saúde. Brasília: ANVISA, 2002.

ASSOCIAÇÃO BRASILEIRA DE NORMAS TÉCNICAS. NBR 5.413: lluminância de interiores. Rio de Janeiro: ABNT, 1992.

ASSOCIAÇÃO BRASILEIRA DE NORMAS TÉCNICAS. NBR 6.022: Artigos científicos impressos. Rio de Janeiro: ABNT, 2018.

ASSOCIAÇÃO BRASILEIRA DE NORMAS TÉCNICAS. NBR 9.050: Acessibilidade de pessoas portadoras de deficiências a edificações, espaço, mobiliário e equipamentos urbanos. Rio de Janeiro: ABNT, 2015.

ASSOCIAÇÃO BRASILEIRA DE NORMAS TÉCNICAS. NBR 10.520: Citações em documentos. Rio de Janeiro: ABNT, 2002.

ANDRETO, Luiz F.M. Influência do espaço construído na produtividade: Avaliação baseada na ergonomia do ambiente construído e na psicologia dos espaços de trabalho. Recife: PPGEP-UFPE, 2005.

CAVALCANTI, Patrícia Biasi. Qualidade da iluminação em ambientes de internação hospitalar. Disponível em: $<$ http://www.iar.unicamp.br/lab/luz/ld/Arquitetural/Sa\%FAde/qualidade_da_iluminacao_em_ambi ents_de_internacao hospitalar.pdf>. Acesso em: 06 dez. 2018.

FERRER, Nicole; LÔBO, Marcella; FULGÊNCIO, Vinícius. Consultórios integrados: estudo de caso em estabelecimento assistencial de saúde no Recife. III ENEAC - Encontro Nacional de Ergonomia do Ambiente Construído. João Pessoa: III ENEAC, 2011.

IIDA, Itiro. Ergonomia: projeto e produção. São Paulo: Editora Blucher, 2005.

MACEDO, Cláudio. A Iluminação que facilita a aprendizagem. Sergipe: Saense, 2016. Disponível em: <http://www.saense.com.br/2016/05/a-iluminacao-que-facilita-a-aprendizagem/>. Acesso em: 07 dez. 2018.

OKITA, Naila. lluminação natural em sala de aula melhora aprendizado e saúde dos alunos. São Paulo: USP, 2008.2 Disponível em: $<$ https://www.diariodasaude.com.br/news.php?article=iluminacao-natural-em-sala-de-aulamelhora-aprendizado-e-saude-dos-alunos\&id=3330 >. Acesso em: 02 dez. 2018.

PECCIN, Adriana. Iluminação Hospitalar. Estudo de Caso: espaços de internação e recuperação. Porto Alegre: PROPAR-UFRGS, 2002. Disponível em: $<$ https://www.lume.ufrgs.br/bitstream/handle/10183/3213/000333963.pdf?sequee=1> Acesso em: 29 mar. 2019.

VILLAROUCO, Vilma. An ergonomic look at the work environment, Proceeding from IEA 09: 17th World Congress on Ergonomics. China: Beijing, 2009.

VILLAROUCO, Vilma. Avaliação Ergonômica do projeto arquitetônico. XII Congresso Brasileiro de Ergonomia VI Congresso Latino-Americano de Ergonomia e I Seminário Brasileiro de Acessibilidade Integral. Recife: Anais, 2002. 